\title{
Responses of growth rate, pigment composition and optical properties of Cryptomonas sp. to light and nitrogen stresses
}

\author{
A. Sciandra ${ }^{1, *}$, L. Lazzara ${ }^{2}$, H. Claustre ${ }^{3}$, M. Babin ${ }^{3}$ \\ ${ }^{1}$ Laboratoire d'Océanographie Biologique et Ecologie du Plancton Marin, ESA-CNRS 7076, Université P.M. Curie Paris VI, \\ Station Zoologique, BP 28, 06234 Villefranche-sur-Mer, France \\ ${ }^{2}$ Dipartimento di Biologia Vegetale, via Micheli 1, 50121 Firenze, Italy \\ ${ }^{3}$ Laboratoire de Physique et Chimie Marines, ESA-CNRS 7077, Université P.M. Curie Paris VI, BP08, La Darse, 06238 \\ Villefranche-sur-Mer, France
}

\begin{abstract}
The cryptophyte Cryptomonas sp. was cultured in nitrogen- and light-limited conditions to investigate relationships between inherent optical properties (absorption and fluorescence), pigment contents, N/C ratio and somatic growth rate. The 2 limitations induced large variations in phycoerythrin (PE) and chlorophyll $a(\mathrm{chl}$ a) contents, with a significantly higher variation in PE than chl a under nitrogen stress. Under $\mathrm{N}$ limitation, there is a significant relationship between the PE/chl a ratio and the growth rate. In the case of light perturbation, the ratio PE/chl a was slightly modified during photoacclimation. Emission and excitation spectra of PE and chl a showed that the coupling efficiency between these pigments is less affected by nitrogen than by light changes. It is suggested that transfer of energy between PE and chl $a$ is regulated differently when growth is limited by light or nitrogen. Under nitrogen deprivation, the pool of PE is preferentially degraded to reduce the energy transmitted to chl $a$, and to support the $\mathrm{N}$ demand. Under a light change, the energy harvested by PE and transferred to chl $a$ is regulated by the coupling efficiency between the 2 pigments, and secondarily by synthesis or degradation of the PE quota. For each limitation, different relationships are shown between optical characteristics based on fluorescence ratios and growth rate.
\end{abstract}

KEY WORDS: Cryptophyceae $\cdot$ Growth rate $\cdot$ Quota $\cdot$ Chlorophyll a Phycoerythrin $\cdot$ Absorption · Fluorescence $\cdot$ Photoacclimation $\cdot$ Nitrogen limitation $\cdot$ Light limitation

\section{INTRODUCTION}

Cryptophytes and some rhodophytes can be distinguished from other eucaryotic micro-algae by the presence of green-orange absorbing phycobiliproteins (PBPs). Different PBPs have been studied essentially in Cyanophyceae: allophycocyanin (AP), phycocyanin (PC) and phycoerythrin (PE), which harvest photons at different wavelengths $(\lambda)$ between 520 and $660 \mathrm{~nm}$. Clustered within phycobilisomes at the surface of thylakoids, these biliproteins constitute the major light-

*E-mail: sciandra@obs-vlfr.fr harvesting pigments. The light-harvesting system in the Cryptophyceae differs from that in the Cyanophyceae and Rhodophyceae; it does not consist of phycobilisomes and contains only a single biliprotein, PC or PE (Rowan 1989). Electron microscopic studies indicate that the biliproteins may be positioned within the intrathylakoidal spaces (Gantt et al. 1971).

As the amount of cell PE depends simultaneously upon light and nitrogen conditions, it is difficult to distinguish the different acclimation modes of Cryptophyceae to environmental factors. Abundance and composition of chromoproteins seem to follow 3 major regulations: (1) Chromatic adaptation fits the pigment composition to the spectral composition of the photo- 
synthetically available radiation (PAR) (Tandeau de Marsac \& Houmard 1988, 1993, Grossman 1990, Grossman et al. 1994, Campbell 1996). (2) Photoacclimation regulates the amount of cell pigments to optimize the flux of energy absorbed by the cells as a function of irradiance and their metabolic requirements (Kana \& Glibert 1987a,b). (3) The PBP pool is dependant on nitrogen availability. The relationship between the $\mathrm{N}$ status and the PBP content is not straightforward, because it reflects at least 2 kinds of metabolic regulation. Firstly, when nitrogen-limiting conditions lead to unbalanced fluxes of $\mathrm{C}$ and $\mathrm{N}$, carbon fixation is downshifted by reducing the energy transferred from PBPs to Photosystem II (PSII) (Allen et al. 1990, Turpin 1991). This uncoupling may parallel the denaturation of PBPs. Secondly, it is hypothesized that PBPs constitute cell reserves in the case of nitrogen deprivation (Carr 1988). For instance, non-nitrogen-fixing cyanobacteria can use their PBPs by degrading the linker polypeptides of phycobilisomes, inducing rapid cell bleaching (Collier \& Grossman 1992, 1994). Wyman et al. (1985) have suggested that Synechococcus sp. Strain DC2 can develop a nonphotosynthetic pool of free PE usable as a nitrogen source if necessary, but this point is under debate (Glibert et al. 1986, Kana \& Glibert 1987b). Degradation may be passive (no synthesis of new biliproteins during cell division leading to progressive pigment dilution) or active (breakdown of existing biliproteins). Different studies have shown that the nitrogen from protease PBP degradation (Foulds \& Carr 1977, Woods \& Haselkorn 1980) is used for the synthesis of new proteins (Allen \& Hutchison 1980, Boussiba \& Richmond 1980, Duke \& Allen 1990). Kana et al. (1992) have noticed specific adaptations in different natural strains of Synechococcus confronted with $\mathrm{N}$ limitation. Oceanic species, unable to store important reserves and exposed to variable nutritive conditions, retain their phycobilisomes for some time after nitrogen deprivation. This allows them to quickly resume optimal photosynthetic activity in the event of $\mathrm{N}$ enrichment. Inversely, this adaptive strategy does not exist in coastal strains, in which $\mathrm{N}$-limiting conditions lead rapidly to the breakdown of phycobilisomes and synthesis of new proteins.

Most studies concerning phytoplankton acclimation focus on the response of growth to either photon or nutrient flux. However, the growth response to the most limiting factor (sensu Liebig 1840) is not independent from the state of any other factor, if the latter is at a suboptimal level (Sciandra et al. 1997). In dynamic environments such as fronts or tidal regions, mesoscale and submesoscale motions can induce rapid variations in cellgrowth factors, forcing phytoplanktonic communities to adapt their metabolism to the nature of the limitation. Since nutrient and photon fluxes govern metabolic N and $\mathrm{C}$ pathways which are internally coupled, the study of a common cell index responding to both these fluxes, as PE or chl a, should provide new insights into the adaptive processes involved. In contrast to cyanobacteria, marine Cryptophyceae have been poorly studied. This work presents experimental results on how Cryptomonas sp. regulates its internal pool of PBPs to optimize its growth rate under light and nitrogen stresses. Symbols and units used herein are listed in Table 1.

\section{MATERIALS AND METHODS}

Cultures. The Cryptomonas sp. strain was isolated from natural populations in the Gulf of Naples (Thyrrenian Sea) by L.L. and maintained in $\mathrm{f} / 2$ Guillard medium at $19^{\circ} \mathrm{C}$. To induce nitrogen $(\mathrm{N})$ enrichment and starvation of Cryptomonas sp. cells, two $5 \mathrm{l} \mathrm{NO}_{3}$ limited continuous cultures were exposed continuously to similar PAR and constant temperature $\left(20^{\circ} \mathrm{C}\right)$. Details for the chemostats and enriched sea-water composition are described in Bernard et al. (1996). In the LN-HN (low $\mathrm{N} \rightarrow$ high $\mathrm{N}$ ) culture (PAR $=112 \mu \mathrm{mol}$ quanta $\mathrm{m}^{-2} \mathrm{~s}^{-1}$ in the center of the reactor), cells previously $\mathrm{N}$-starved were submitted to a $\mathrm{NO}_{3}$ pulse $(250 \mu \mathrm{M}$ ). In the HN-LN (high $\mathrm{N} \rightarrow$ low $\mathrm{N}$ ) culture $\left(\right.$ PAR $=95 \mu \mathrm{mol}$ quanta $\left.\mathrm{m}^{-2} \mathrm{~s}^{-1}\right), \mathrm{N}$ limitation was achieved by replacing the previous renewal medium with one lacking $\mathrm{NO}_{3}$. Fig. 1 shows how the dilution rates $\left(D_{t}\right)$ and the $\mathrm{NO}_{3}$ concentration in the renewal medium were adjusted in order to maintain concentrated suspensions of Cryptomonas sp. in each chemostat before and after $\mathrm{N}$ perturbations. The effects of PAR variation were studied in one 61 batch HL-LL (high light $\rightarrow$ low light) culture. Cells were previously adapted to high PAR (550 $\mu \mathrm{mol}$ quanta $\left.\mathrm{m}^{-2} \mathrm{~s}^{-1}\right)$ over $9 \mathrm{~d}$, during which times the culture was diluted with new medium every $3 \mathrm{~d}$. Twenty-four hours after the last dilution, PAR was reduced to $18 \mu \mathrm{mol}$ quanta $\mathrm{m}^{-2}$ $\mathrm{s}^{-1}$ by covering the culture vessel with a neutral screen.

$\mathrm{NO}_{3}$ and $\mathrm{NO}_{2}$ concentrations were determined with a Technicon chain analyzer. Algae size spectra were obtained with the optical particle counter Hiac-Royco (Pacific Scientific). The frequency of data acquisition was adjusted accordingly to the dilution rate to prevent a decrease in the culture volumes, and was around 1 sampling every $3 \mathrm{~h}$ for the particle counts and $1 \mathrm{sam}$ pling every $6 \mathrm{~h}$ for the $\mathrm{NO}_{3}$ and $\mathrm{NO}_{2}$ measurements. Nutrient and cell counts were monitored by the apparatus described in Bernard et al. (1996). $\mathrm{NH}_{4}{ }^{+}$was occasionally determined in the enrichment medium and in the cultures, and was always undetectable.

Growth rate. The rates of growth $\left(\mu_{V}\right)$ and cell division $\left(\mu_{n}\right)$ were respectively calculated from the variations of biovolume $(v$, the product of cell density and average cell volume) and cell density (n). 
Table 1. List of symbols used

\begin{tabular}{|c|c|c|}
\hline Symbols & Significance & Units \\
\hline$\lambda$ & Light wavelength in vacuo & $\mathrm{nm}$ \\
\hline$\phi_{\mathrm{T}_{\mathrm{PE}-\mathrm{chl} a}}$ & Quantum yield of energy transfer from chl a to phycoerythrin & Dimensionless \\
\hline$\phi_{\mathrm{D}_{\mathrm{PE}}}$ & Quantum yield of heat dissipation & Dimensionless \\
\hline$\phi_{\mathrm{F}_{\mathrm{PE}^{\prime}}} \phi_{\mathrm{F}_{\mathrm{chl}} a}$ & Quantum yield of PE and chl a fluorescence respectively & Dimensionless \\
\hline$\mu_{n}, \mu_{V}$ & Cell division and growth rates, respectively & $\mathrm{d}^{-1}$ \\
\hline$a(\lambda)$ & Absorption coefficient of cell suspension at wavelength $\lambda$ & $\mathrm{m}^{-1}$ \\
\hline$a_{\mathrm{cm}}(\lambda)$ & Absorption coefficient of cellular matter & $\mathrm{m}^{-1}$ \\
\hline$a_{\mathrm{sol}}(\lambda)$ & Absorption coefficient of cellular matter ideally dispersed into solution & $\mathrm{m}^{-1}$ \\
\hline$a^{*}{ }_{\text {extPE }}^{*}(547)$ & Specific absorption coefficient of PE extracted in phosphate buffer & $\mathrm{m}^{-1}$ \\
\hline$d$ & Cell diameter & $\mu \mathrm{m}$ \\
\hline $\mathrm{C}$ & Carbon & - \\
\hline Chl a & Chlorophyll a & - \\
\hline DCMU & Dichlorophenyl dimethylurea & - \\
\hline$D_{t}$ & Dilution rate at time $t$ & $\mathrm{~d}^{-1}$ \\
\hline$E(\lambda)$ & Light energy at wavelength $\lambda$ & Quanta $\mathrm{m}^{-2} \mathrm{~s}^{-1}$ \\
\hline$F\left(\lambda_{\text {ex }}, \lambda_{\text {em }}\right)$ & Fluorescence measured at $\lambda_{\mathrm{em}}$ for an excitation at $\lambda_{\mathrm{ex}}(\mathrm{em}=$ emission $)$ & Quanta $\mathrm{m}^{-3} \mathrm{~s}^{-1}$ \\
\hline F1 & Ratio of PE fluorescence to chl a fluorescence when PE alone is excited & Dimensionless \\
\hline F2 & $\begin{array}{l}\text { Ratio of chl a fluorescence when PE is excited, to chl a fluorescence when chl a } \\
\text { is excited in presence of DCMU }\end{array}$ & Dimensionless \\
\hline HL-LL & Batch culture submitted to light reduction (high light $\rightarrow$ low light) & - \\
\hline $\mathrm{HN}-\mathrm{LN}$ & Continuous culture submitted to $\mathrm{N}$ deprivation (high nitrogen $\rightarrow$ low nitrogen) & - \\
\hline$K_{\mathrm{TPE}-\mathrm{chl} a}$ & Rate constant of PE-chl a energy transfer & $\mathrm{s}^{-1}$ \\
\hline$K_{\mathrm{D}}$ & Rate constant of PE heat dissipation & $\mathrm{s}^{-1}$ \\
\hline$K_{\mathrm{FE}}^{\mathrm{FL}}$ & Rate constant of PE fluorescence & $\mathrm{s}^{-1}$ \\
\hline LN-HN & Continuous culture submitted to $\mathrm{N}$ supply (low nitrogen $\rightarrow$ high nitrogen) & - \\
\hline $\mathrm{N}, \mathrm{NO}_{3}, \mathrm{NO}_{2}, \mathrm{NH}_{4}$ & Nitrogen, nitrate, nitrite and ammonium, respectively & $\mu \mathrm{M}$ \\
\hline PAR & Photosynthetically available radiation & $\mu \mathrm{mol}$ quanta $\mathrm{m}^{-2} \mathrm{~s}^{-1}$ \\
\hline PBP & Phycobiliprotein & - \\
\hline $\mathrm{PE}$ & Phycoerythrin & - \\
\hline$q_{\mathrm{N}}, q_{\mathrm{C}}, q_{\mathrm{PE}}, q_{\mathrm{chl}} \mathrm{a}$ & $\begin{array}{l}\mathrm{N}, \mathrm{C}, \mathrm{PE} \text { and chl a quota, respectively, defined as amount of material per unit } \\
\text { cell volume }\end{array}$ & $\mathrm{mg} \mu \mathrm{m}^{-3}$ \\
\hline$Q_{a}(\lambda)$ & Mean efficiency factor for absorption by phytoplanktonic cells & Dimensionless \\
\hline
\end{tabular}

$$
\mu_{n, V}=\frac{1}{x_{n, V}} \frac{\mathrm{d} x_{n, V}}{\mathrm{~d} t}+D_{t}
$$

where $x_{n, v}$ is the smoothed ( 5 data points average) cell number or cell biovolume, and $D_{t}$ the dilution rate at time $t$.

Spectral absorption. The spectral values of the absorption coefficient $a(\lambda)$ of the algal cells were measured in $1 \mathrm{~cm}$ quartz cuvettes with a dual beam spectrophotometer (DMS-100 Varian) (see Fig. 2). Cuvettes were placed at the entrance of an integrating sphere. Measurements spanned from 380 to $750 \mathrm{~nm}$ with $1 \mathrm{~nm}$ increments, with filtered media from the culture (0.2 $\mathrm{mm}$ syringe filter, Sartorius) used as reference. The significant correlation between a(750) and cell density and total carbon was interpreted as scattering during the absorption measurements. To rectify this bias, we assumed that Cryptomonas sp. exhibits no absorption at $750 \mathrm{~nm}$, and that scattering is wavelength-independent; $a(750)$ was thus simply subtracted from $a(\lambda)$. A final spectrum was obtained by averaging the spectra of 3 different samples corrected for the baseline. Depending on the algal concentration, the reproducibility of the 3 scans ranged between 3 and $10 \%$.

Cell quota. Triplicates of $10 \mathrm{ml}$ were filtered onto precombusted GF/F filters and kept in a dry-heat bath at $60^{\circ} \mathrm{C}$ before particulate carbon and nitrogen analyses were made with a LECO $900 \mathrm{CHN}$ analyzer. For pigment determinations, 10 or $20 \mathrm{ml}$ of culture (depending on the cell concentration) were filtered onto Whatman GF/F filters which were subsequently stored in liquid nitrogen before analysis (performed within 2 mo after sample collection). Extraction was in $3 \mathrm{ml}$ cold methanol with a known amount of $\mathrm{Zn}$ (II) pyropheophorbide octadecyl ester as internal standard (Mantoura \& Repeta 1997). The extraction effi- 
ciency was improved by sonication for $30 \mathrm{~s}$ and the extract was then clarified by filtration (Whatman GF/C). The HPLC procedure is described by Vidussi et al. (1996).
The concentration of PE was indirectly estimated from absorption measurements of a(547) as:

$$
\mathrm{PE}=\frac{a_{\mathrm{SOl}}(547)}{a^{*}{ }_{\operatorname{extPE}}(547)}
$$

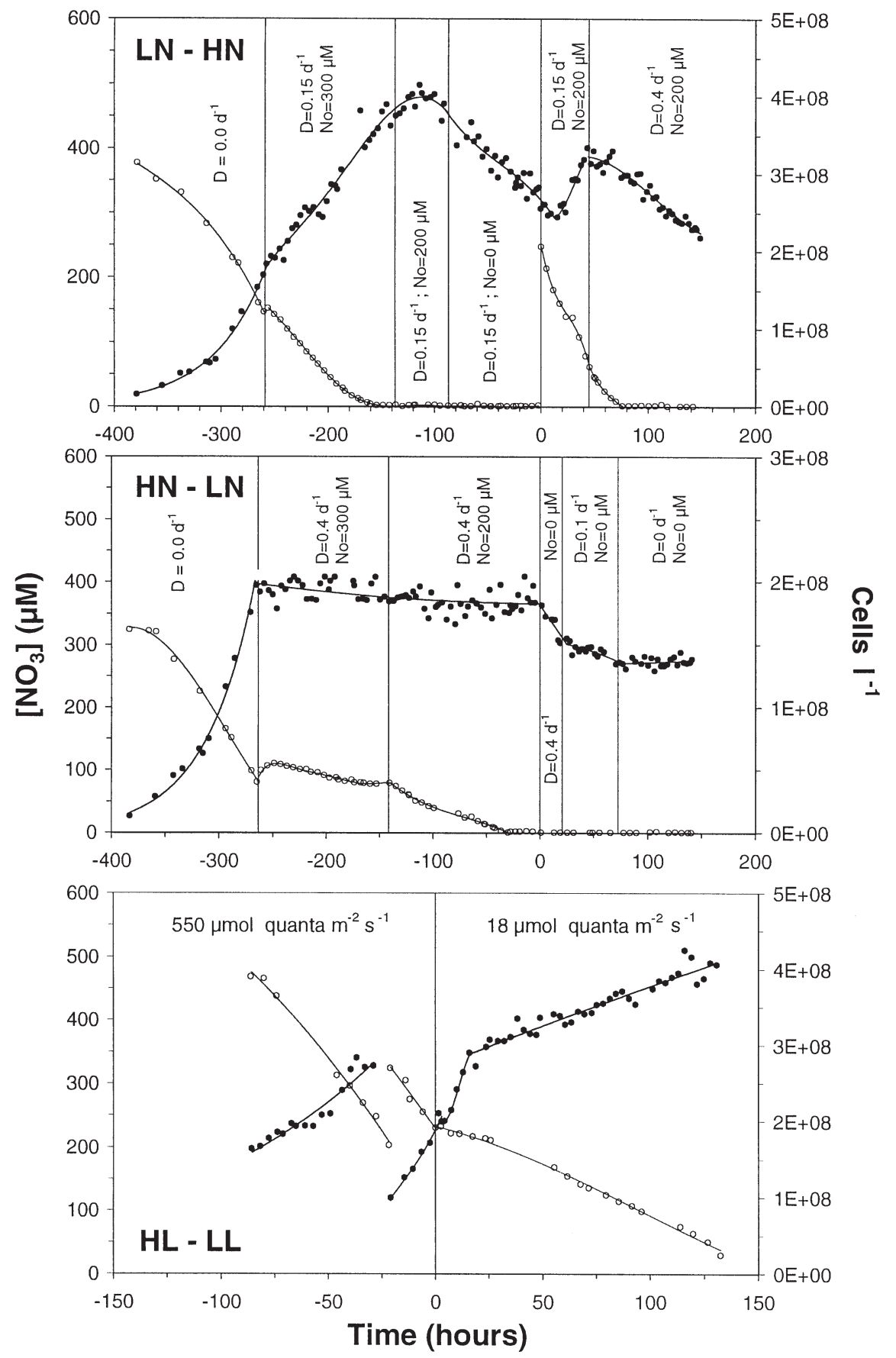

Fig. 1. Cryptomonas sp. Variations in cell density (•) and $\mathrm{NO}_{3}$ concentration (o) in chemostats LN-HN and HN-LN, and in batch culture HL-LL as a function of time. At time $0, \mathrm{NO}_{3}$ was added to $\mathrm{LN}-\mathrm{HN}$, the supply of $\mathrm{NO}_{3}$ was stopped in $\mathrm{HN}-\mathrm{LN}$, and the light was shifted down in HL-LL. Discontinuity at time $-25 \mathrm{~h}$ in HL-LL culture resulted from manual dilution. Vertical bars delimit time periods with different dilution rates $\left(D_{t}\right)$ and $\mathrm{NO}_{3}$ concentrations in enrichment medium (No). LN-HN: low

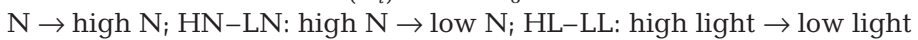


where $a_{\text {extPE }}^{*}(547)$ is the specific absorption coefficient of PE extracted in solution $\left(0.0029 \mathrm{~m}^{2} \mathrm{mg}^{-1}\right.$ in phosphate buffer: MacColl et al. 1976) and $a_{\text {sol }}(547)$ is the theoretical absorption of PE contained in the cells were it unpacked and dissolved in solution, i.e. the extrapolation of a(547) to cells of zero diameter. If the cell phycoerythrin were uniformly distributed in the medium, the absorption coefficient $a_{\text {sol }}(547)$ would be the same as that measured in suspension, a(547), but modified by a flattening factor. The extent of this spectral flattening arising from pigment packaging was expressed by Morel \& Bricaud (1981) as $Q_{a}^{*}(\lambda)$, the ratio of the absorption coefficient of the suspension to the absorp- tion coefficient of the same absorbing material in solution:

$$
Q_{a}^{*}(\lambda)=\frac{a(\lambda)}{a_{\text {sol }}(\lambda)}
$$

which can also be expressed as

$$
Q_{a}^{*}(\lambda)=\frac{3 Q_{a}(\lambda)}{2 \rho^{\prime}}
$$

where $Q_{a}(\lambda)$ is the absorption efficiency of 1 spherical cell with diameter $d$ :

$$
Q_{a}(\lambda)=\frac{4 a(\lambda)}{n_{t} \pi d^{2}}
$$
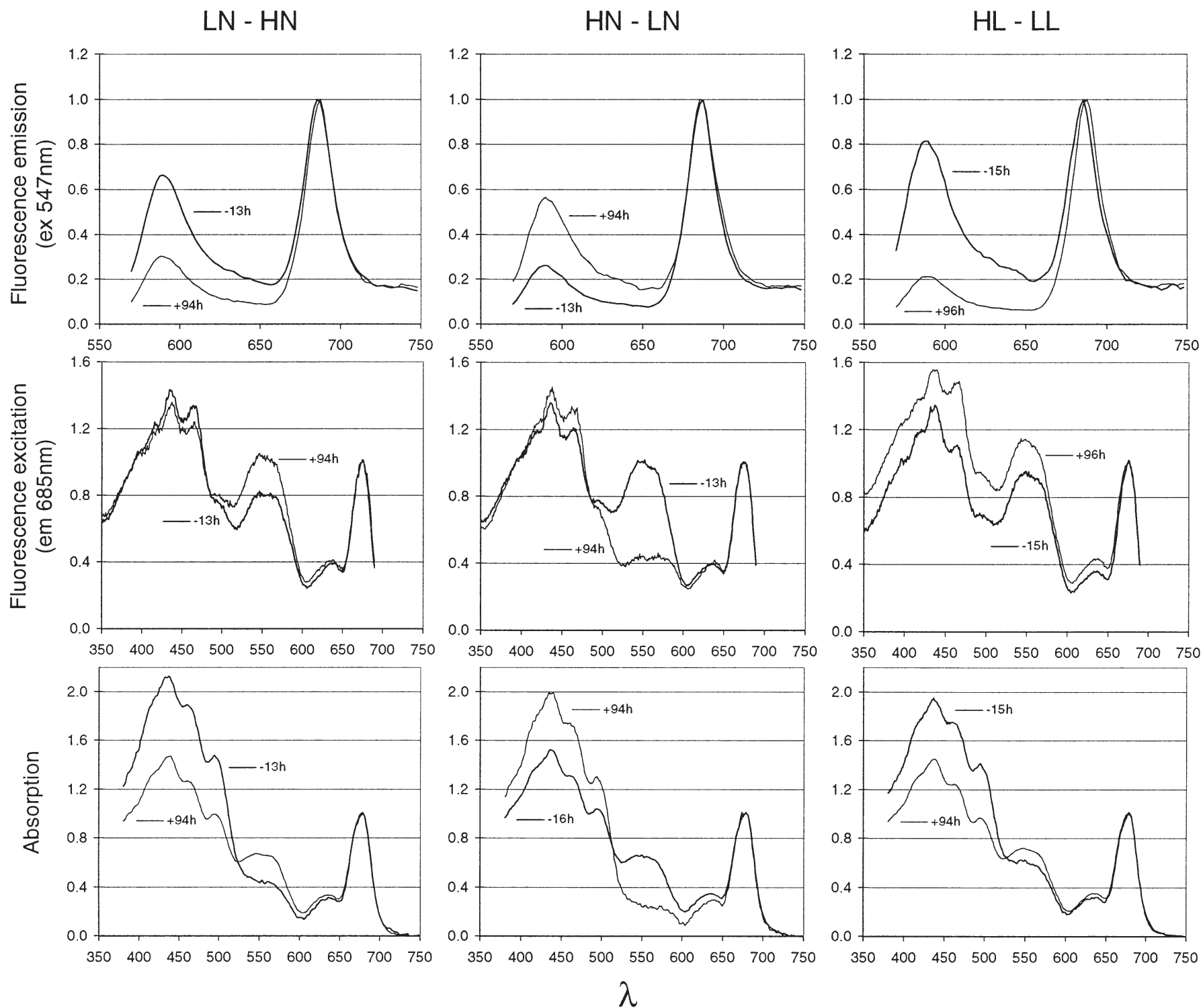

Fig. 2. Cryptomonas sp. Examples of fluorescence emission (ex $547 \mathrm{~nm}$ ), fluorescence excitation (em $685 \mathrm{~nm}$ ) and absorption spectra, normalized to their maxima and to red peak, respectively, just before and $4 \mathrm{~d}$ after $\mathrm{NO}_{3}$ and light shifts 
$n_{t}$ being the cell concentration. $\rho^{\prime}$ is the product of $d$ and $a_{\mathrm{cm}}(\lambda)$, the absorption of cell material, is

$$
a_{\mathrm{cm}}(\lambda)=\frac{6 a_{\mathrm{sol}}(\lambda)}{n_{t} \pi d^{3}}
$$

$Q_{a}(\lambda)$, for spherical particles (van de Hulst 1957), has a monotonic non-linear relationship with $\rho^{\prime}$ :

$$
Q_{a}(\lambda)=1+2 \frac{\mathrm{e}^{-\rho^{\prime}}}{\rho^{\prime}}+2 \frac{\mathrm{e}^{-\rho^{\prime}}-1}{\rho^{\prime 2}}
$$

Then, using the value of $Q_{a}$ calculated from Eq. (5), it is possible to solve numerically Eq. (6) to obtain the values of $\rho^{\prime}, a_{\mathrm{cm}}(\lambda)$ and $a_{\mathrm{sol}}(\lambda)$.

The package-effect for PE and chl a absorption can be seen in Fig. $3 a, b$, where the ratio of $a(\lambda)$ to $a_{\text {sol }}(\lambda)$ decreases with increasing the pigment concentration. The data points form a clear curvilinear relationship because: (1) the cell concentration was stable in chemostats and, therefore, $a(\lambda)$ variations reflect essentially changes in $\rho^{\prime}$ and (2) in the HL-LL culture, variations in the cell concentrations are well-correlated with $\rho^{\prime}$. In order to test the validity of this method in estimating the pigment concentration, Eqs. (2) \& (4) were applied to chl a absorption values at $678 \mathrm{~nm}$, taking a specific absorption coefficient of $0.020 \mathrm{~m}^{2} \mathrm{mg}^{-1}$. The calculation of $a_{\text {sol }}(678)$ provides a linear relationship
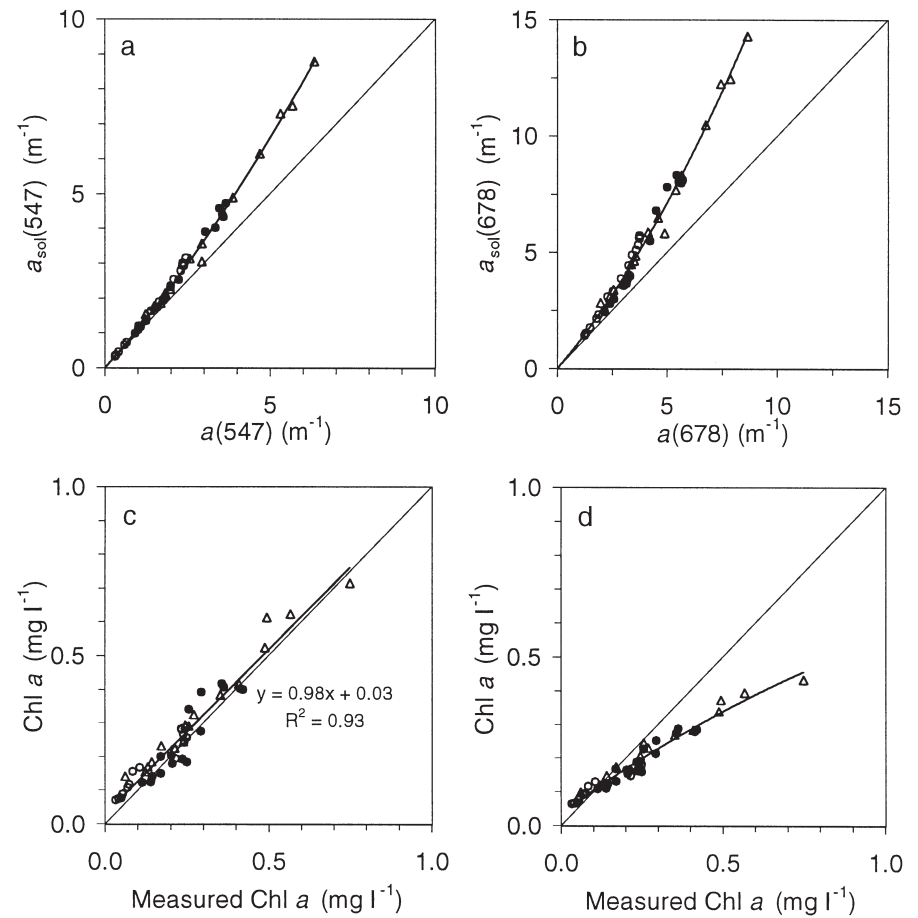

Fig. 3. Cryptomonas sp. (a,b) Comparison of in vivo absorption and $a_{\text {sol }}$ at (a) $547 \mathrm{~nm}$ and (b) $678 \mathrm{~nm}$. (c,d) Comparison of the chl a measured by HPLC with the chl a calculated from in vivo absorption at $678 \mathrm{~nm}$ (c) after and (d) without correction for package effect (see 'Materials and methods') between measured and calculated chl a (Fig. 3c), whereas the use of $a(678)$ provides a curvilinear and underestimated estimation of the measured chl a because of the packaging-effect (Fig. 3d).

$q_{\mathrm{N}}, q_{\mathrm{C}}, q_{\mathrm{PE}}$ and $q_{\mathrm{chl}}$ a denote, respectively, the $\mathrm{N}, \mathrm{C}$, $\mathrm{PE}$ and chl a quota, defined as the amount of material per unit cell volume.

Fluorescence spectra. Fluorescence excitation and emission spectra at room temperature were measured on Cryptomonas sp. suspensions in $1 \mathrm{~cm}$ quartz cuvettes, using quantum-correcting (oxazin and rhodamine) fluorescence spectrometers (PerkinElmer, LS5b and Spex, Fluorolog 2). The photosynthesis inhibitor DCMU was added at a final concentration of $20 \mu \mathrm{M}$, and the filtered samples were used for blank subtraction (Lazzara et al. 1996). Emission spectra were scanned both in the range 600 to $750 \mathrm{~nm}$ with excitation of chlorophyll $a$ at $440 \mathrm{~nm}$, and in the range 570 to $750 \mathrm{~nm}$ with excitation of PE at $547 \mathrm{~nm}$. All emission spectra were corrected for the instrument spectral response using a Li-Cor calibrated $200 \mathrm{~W}$ quartz-halogen tungsten filament lamp with known spectral irradiance (Li-Cor calibrator, LI1800-02). Excitation spectra were measured with emission at $685 \mathrm{~nm}$ in the range 350 to $690 \mathrm{~nm}$ and with emission at $730 \mathrm{~nm}$ in the range 350 to $690 \mathrm{~nm}$. The relative variations of the energy transfer from PE to chl $a$ were assessed by using 2 fluorescence $\left[F\left(\lambda_{\text {ex }}, \lambda_{\text {em }}\right)\right]$ ratios obtained from the emission spectrum of PE and the excitation spectrum of chl a (Fig. 2).

$\mathrm{F} 1$ is defined as the ratio of PE fluorescence to chl a fluorescence when PE alone is excited in the presence of DCMU:

$$
\mathrm{F} 1=\frac{F(547,590)}{F(547,685)}
$$

where: $F(547,590)=E(547) a(547) \phi_{\mathrm{F}_{\mathrm{PE}}}$ and $F(547,685)=E(547) a(547) \phi_{\mathrm{F}_{\text {chl }} a} \phi_{\mathrm{T}_{\mathrm{PE}-\text { chl } a^{\prime}}}$ and $E(\lambda) a(\lambda)=$ energy absorbed at wavelength $\lambda$.

The energy of each photon absorbed at $547 \mathrm{~nm}$ may be either transferred to chl $a$, dissipated as heat, or re-emitted as fluorescence at $590 \mathrm{~nm}$. Energy transfer (T), dissipation (D), and fluorescence $(\mathrm{F})$ occur with probabilities defined by the following respective quantum yields:

$$
\begin{gathered}
\phi_{\mathrm{T}_{\mathrm{PE}-\text { chl } a}}=\frac{K_{\mathrm{T}_{\mathrm{PE}-\text { chla }}}}{K_{\mathrm{FPE}}+K_{\mathrm{D}_{\mathrm{PE}}}+K_{\mathrm{TPE}-\text { chla }}} \\
\phi_{\mathrm{D}_{\mathrm{PE}}}=\frac{K_{\mathrm{D}_{\mathrm{PE}}}}{K_{\mathrm{F}_{\mathrm{PE}}}+K_{\mathrm{D}_{\mathrm{PE}}}+K_{\mathrm{T}_{\mathrm{PE}-\text { chla }}}} \\
\phi_{\mathrm{F}_{\mathrm{PE}}}=\frac{K_{\mathrm{F}_{\mathrm{PE}}}}{K_{\mathrm{F}_{\mathrm{PE}}}+K_{\mathrm{D}_{\mathrm{PE}}}+K_{\mathrm{T}_{\mathrm{PE}-\text { chla }}}}
\end{gathered}
$$

where $\phi_{\mathrm{T}_{\mathrm{PE}-\text { chl a }}}+\phi_{\mathrm{D}_{\mathrm{PE}}}+\phi_{\mathrm{FPE}}=1$ and $K_{\mathrm{TPE}-\text { chl a }}$ $K_{\mathrm{DPE}}$ and $K_{\mathrm{PE}}=$ rate constants of the different processes, respectively. It follows that: 


$$
\mathrm{F} 1=\frac{1}{\phi_{\mathrm{F}_{\mathrm{chl} a}}} \frac{K_{\mathrm{F}_{\mathrm{PE}}}}{K_{\mathrm{T}_{\mathrm{PE}-\mathrm{chl} a}}}
$$

F1 increases when $K_{\mathrm{TPE}-\mathrm{chl} a^{\prime}}$ the transfer rate from $\mathrm{PE}$ to $\mathrm{chl} a$, is reduced.

F2 is defined as the ratio of chl a fluorescence when $\mathrm{PE}$ is excited to chl a fluorescence when chl $a$ is excited at $440 \mathrm{~nm}$ in the presence of DCMU:

$$
\mathrm{F} 2=\frac{F(547,685)}{F(440,685)}
$$

where $F(547,685)$ is as previously defined, and $F(440,685)=E(440) a(440) \phi_{\mathrm{F}_{\mathrm{chl}} \text { a }}$. After simplification, this reads as:

$$
\mathrm{F} 2=\frac{a(547)}{a(440)} \phi_{\mathrm{T}_{\mathrm{PE}-\mathrm{chl} a}}
$$

F2 increases both with $\phi_{\mathrm{T}_{\mathrm{PE}-\mathrm{chl} a}}$ the $\mathrm{PE}-\mathrm{chl} a$ energy-transfer efficiency, and with the PE to chl $a$ absorption ratio, which approximates the pigment-quota ratio.

\section{RESULTS}

\section{Growth rate}

The growth $\left(\mu_{v}\right)$ and division $\left(\mu_{n}\right)$ rates in the LN-HN cultures declined progressively during the starvation period and increased as expected after the nitrate pulse (Fig. $4 \mathrm{a}$ ). In HN-LN, $\mu_{v}$ and $\mu_{\mathrm{n}}$ were both equal to dilution rate $\left(0.40 \mathrm{~d}^{-1}\right)$ before Time 0 , and fell rapidly after $\mathrm{N}$ deprivation commenced (Fig. 4b). In each of the N-limited cultures, $\mu_{V}$ and $\mu_{n}$ were very similar before $\mathrm{N}$ perturbation, but showed divergent trends thereafter. In both cases, the division rate changed more rapidly than the growth rate, at least during the 2 days after Time 0 . In the HL-LL culture, the division rate seemed first to be enhanced after the light shift-down, and then decreased significantly to approximately $0.1 \mathrm{~d}^{-1}$ (Fig. 4c). Growth rate showed an important reduction immediately after light reduction, and became similar to the division rate after $1 \mathrm{~d}$. Incorporation of $\mathrm{NO}_{3}$ was equally significantly reduced (see Fig. 1) by the shift-down in light.

Mean cell size reacted significantly to change in growth conditions (Fig. 5). Nitrate deprivation and enrichment induced respectively an increase and a decrease in cell diameter. The light shift-down in HL-LL produced a rapid and transient reduction in cell size, showing that somatic growth was immediately inhibited by low light. Finally, light and $\mathrm{N}$ limitations had opposite effects on cell size.

\section{Cell quota}

N/C variations in LN-HN and $\mathrm{HN}-\mathrm{LN}$ were consistently opposite in all conditions of $\mathrm{N}$ limitation and enrichment tested (Fig. 6a). In LN-HN, the lower N/C ratio before $\mathrm{NO}_{3}$ addition (Time 0) was slightly higher than that in HN-LN at the end of the experiment. To attain a higher degree of $\mathrm{N}$ limitation in LN-HN, $D_{t}$ should have been set to 0 instead of $0.15 \mathrm{~d}^{-1}$ (see Fig. 1). A non-zero dilution rate was nevertheless
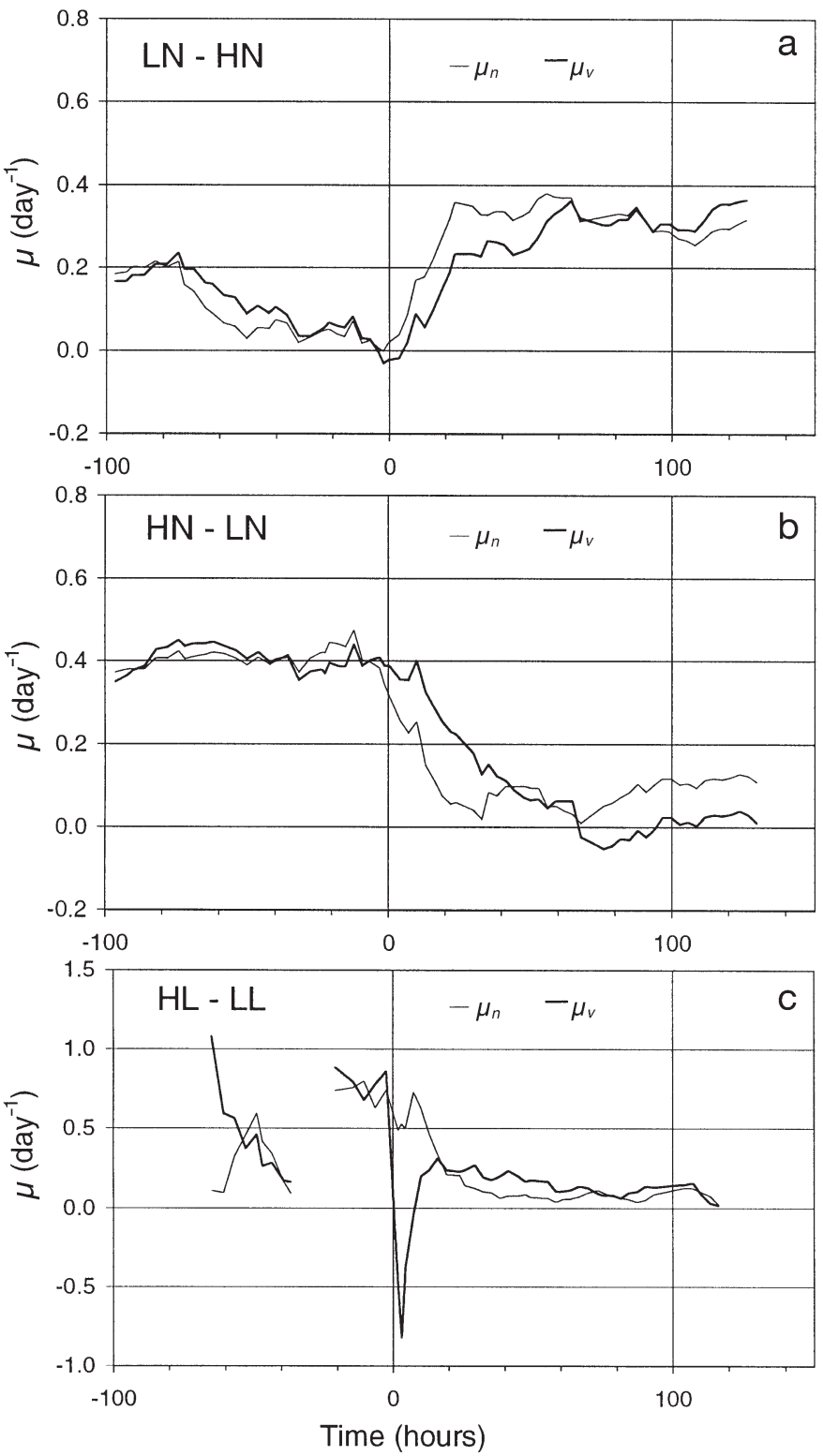

Fig. 4. Cryptomonas sp. Change in cell division $\left(\mu_{n}\right)$ and growth rate $\left(\mu_{v}\right)$ in (a) LN-HN, (b) HN-LN, and (c) HL-LL cultures over time 


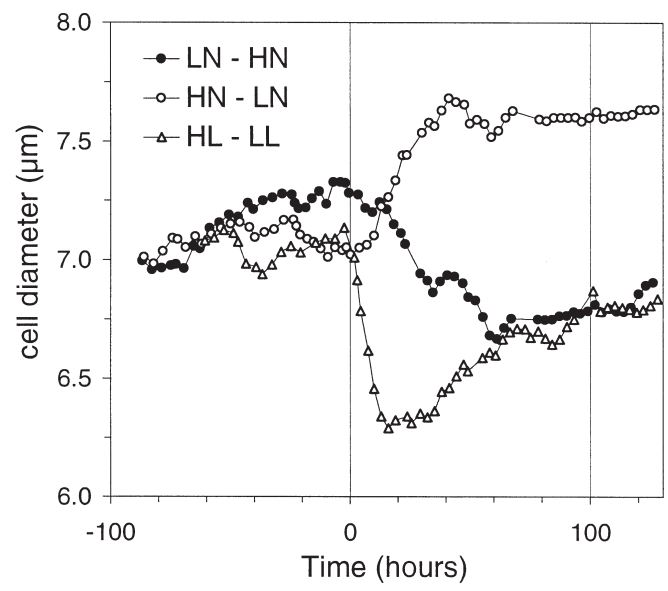

Fig. 5. Cryptomonas sp. Changes in mean cell diameter in LN-HN, HN-LN and HL-LL cultures over time

maintained to compensate loss of culture from repeated sampling. Before $\mathrm{N}$ perturbation, the difference in the N/C ratio was essentially due to the difference in $q_{\mathrm{N}}$ (Fig. 6b). In HN-LN, $q_{\mathrm{N}}$ began to decrease before Time 0 , suggesting that $\mathrm{N}$ limitation occurred early, because of $\mathrm{NO}_{3}$ exhaustion in the chemostat $48 \mathrm{~h}$ before Time 0 (see Fig. 1). $q_{\mathrm{C}}$ remained nearly stable and similar in both HN-LN and LN-HN (Fig. 6c), whereas, reflecting variations in cell volume (Fig. 5), carbon per cell increased and decreased in the $\mathrm{N}$-deprived and $\mathrm{N}$-enriched cultures respectively (Fig. 6d). Thus, when growth is N-limited, N/C, N per cell and $q_{\mathrm{N}}$ showed similar trends, since carbon per cell and cell volume remained correlated. At Time 0 , the N/C ratios were identical in HN-LN and HL-LL, whereas $q_{\mathrm{N}}$ and $q_{\mathrm{C}}$ were significantly higher in the HL-LL culture, due to its exposure to higher irradiance. Reduction in light initially induced a transient increase in $q_{\mathrm{N}}$ and $q_{\mathrm{C}}$, possibly due to the observed drop in cell volume without concurrent loss of intracellular material. The increase in N/C observed after Time 0 indicates that the loss of internal $\mathrm{C}$ was globally greater than the loss of internal N.

Before Time 0, the chl a quota $\left(q_{\mathrm{chl}}\right)$ was governed by the different nutrient and light conditions (Fig. 7a). For HN-LN and LN-HN, which were exposed to similar PARs, $q_{\mathrm{chl} \mathrm{a}}$ mirrored the N/C ratio. The intermediate value obtained for the non N-limited culture HL-LL reflects photoacclimation to higher PAR. After Time 0, the respective $\mathrm{N}$ and PAR perturbations for $\mathrm{LN}-\mathrm{HN}$ and HL-LL led to similar increases in $q_{\text {chl al }}$ which stopped earlier in LN-HN, as indicated by saturation of the N/C ratio. The amplitude of variation in $q_{\mathrm{chl}}$ was higher in the light-perturbed culture $\left(0.86 \mathrm{mg} \mathrm{mm}^{-3}\right)$ than in the $\mathrm{N}$-perturbed cultures $\left(0.65 \mathrm{mg} \mathrm{\mu m}^{-3}\right)$, whereas the vari-
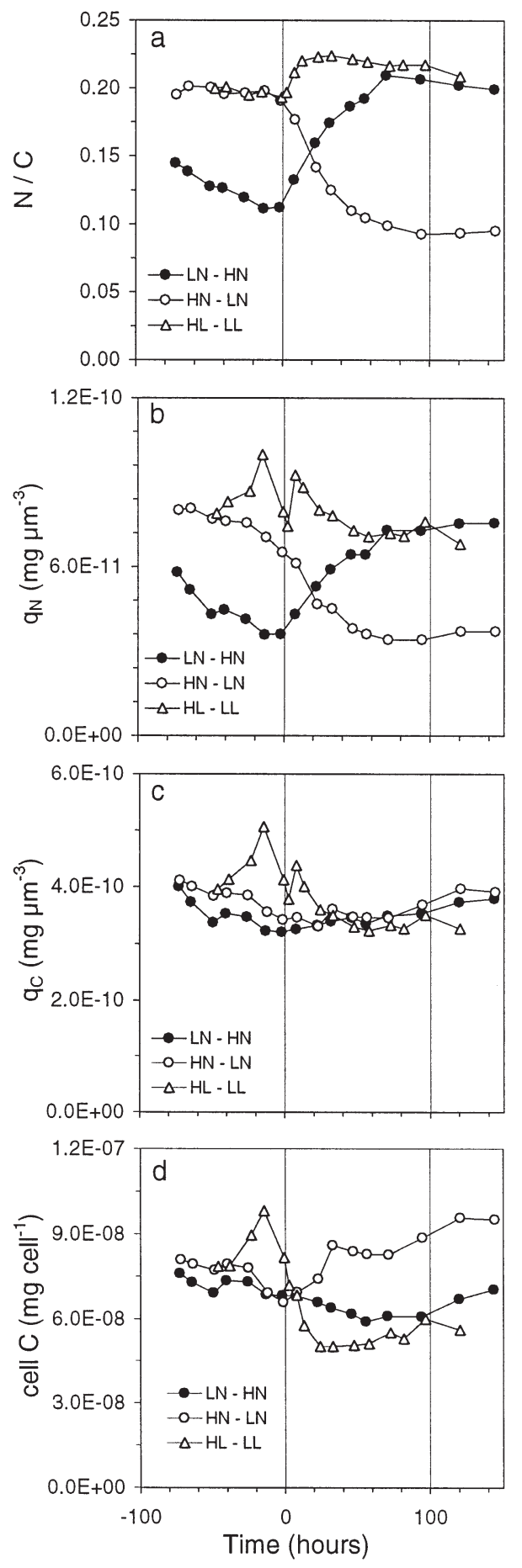

Fig. 6. Cryptomonas sp. Change in (a) N/C ratio, (b) nitrogen quota, $q_{\mathrm{N}}$, (c) carbon quota, $q_{\mathrm{C}}$, and (d) carbon per cell in LN-HN, HN-LN, and HL-LL cultures over time

ation in $q_{\mathrm{PE}}$ (Fig. 7 b) was similar in both treatments (3.0 and $3.1 \mathrm{mg} \mathrm{\mu m}^{-3}$ respectively). The PE/chl a ratio was higher in the light-limited culture (4.2), but was not very different from that in the $\mathrm{N}$-enriched chemostat (4.0). The highest variation in this ratio occurred in the 

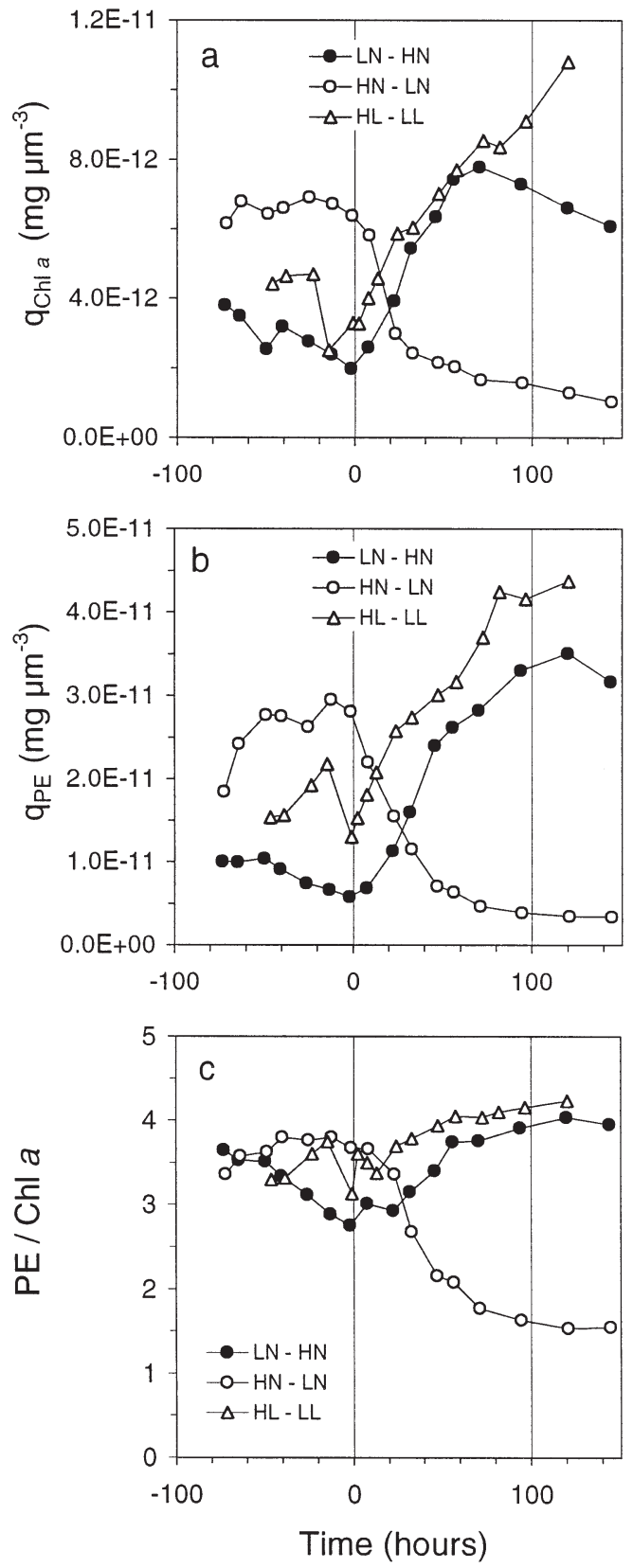

Fig. 7. Cryptomonas sp. Changes in (a) the chl a and (b) PE quota, and (c) $\mathrm{PE} / \mathrm{chl}$ a ratio in $\mathrm{LN}-\mathrm{HN}, \mathrm{HN}-\mathrm{LN}$, and HL-LL cultures over time

fully $\mathrm{N}$-limited chemostat (0.37 to 0.15$)$. As the ratio $\mathrm{PE} / \mathrm{chl}$ a varied always in the same direction as $q_{\mathrm{PE}}$ and $q_{\text {chl al }}$ it can be inferred from Fig. 7 that $N$ stresses induced relatively more important changes in PE than in chl a than light stress.

Fig. 8a,b shows how the chl $a$ and PE quota varied with $\mathrm{N}$ status in the $\mathrm{N}$-perturbed cultures $\mathrm{HN}-\mathrm{LN}$ and LN-HN. The $q_{\mathrm{chl} \text { a }}$ and $q_{\mathrm{PE}}$ values increased by factors of 7.5 and 13 , respectively, reflecting a greater mobility of PE compared to chl a. The ratio PE/chl a was also correlated with the N/C ratio; it ranged from 0.10 to 0.21 (Fig. 8c). In Fig. 8, where 2 variables are plotted against each other, the curves reveal different dynamics. In the case of $\mathrm{N}$ deprivation, the PE/chl a ratio remained stable for several hours (whereas the respective values of $q_{\mathrm{PE}}$ and $q_{\mathrm{chl} \text { a }}$ changed significantly during the same period (Fig. 7a,b), and then decreased as a result of a higher rate of degradation for $q_{\mathrm{PE}}$ than for $q_{\text {chl a }}$. The reverse was observed in the case of $\mathrm{N}$ enrichment, which induced similar rates of $\mathrm{PE}$ and chl a synthesis on a short time-scale, and later a higher rate of PE synthesis.

\section{Fluorescence}

Fig. 9 shows that light and $\mathrm{N}$ perturbations induced clear variations in the fluorescence ratios. F2 is not uniquely an indicator of energy coupling per se, since it is also dependent on the relative amounts of PE and chl a (Fig. 9a, Eq. 8). The relative variations in F2 and $\mathrm{PE} / \mathrm{chl}$ a ratios (Fig. $7 \mathrm{C}$ ) were very similar. In contrast, F1 depended only on PE-absorbed light, whose energy was either transmitted to chl a or re-emitted by PE fluorescence. The highest variation in F1 was in the lightperturbed culture (Fig. 9b), in which the corresponding PE/chl a varied less (Fig. 7c).

\section{DISCUSSION}

\section{Relationships between $q_{\mathrm{N}}, q_{\mathrm{PE}}$, and $q_{\mathrm{chl} \text { a }}$ under light and $\mathrm{N}$ stresses}

PE was estimated assuming that the value determined by MacColl et al. (1976) for PE in phosphate buffer is the same as that in the cell. As the solutions in which phycobiliproteins are extracted differ from the cell cytoplasm, their conformation and consequently their absorption spectrum may be modified (Glazer 1981, Rowan 1989). This could lead to an incorrect estimation of cell PE, with a constant error. Another source of bias is the effect of the $\mathrm{N}$ status on the absorption spectrum of PE. The degradation of PE probably releases free intracellular erythrobilins absorbing at different wavelengths. As their lifetime in the cytoplasm is unknown, it is difficult to estimate how they might interfere with the remaining non-degraded PE. By using absorption at $547 \mathrm{~nm}$ to estimate cell PE, we have assumed that such interference can be ignored, and that the only error in estimation is in the absolute value of cell PE, arising from application of a specific absorption coefficient that can differ between cell and solution. 

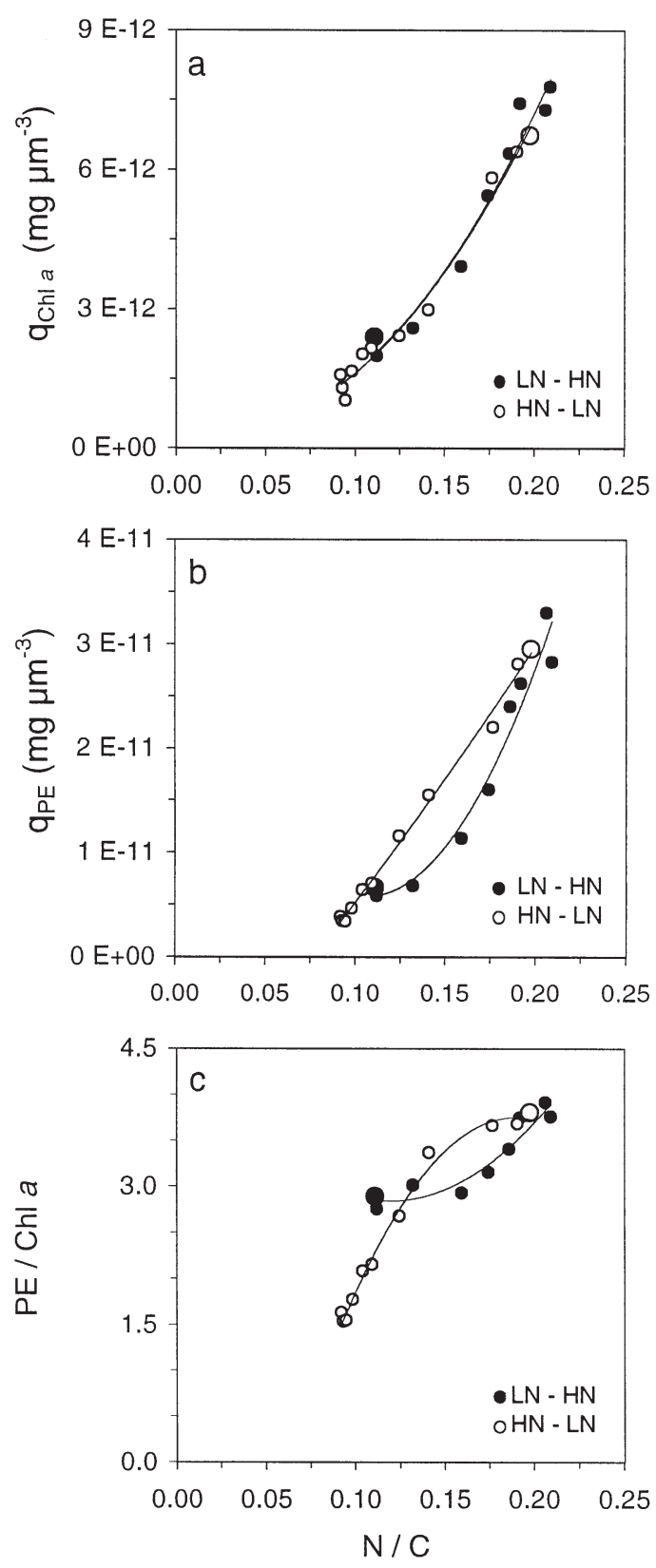

Fig. 8. Cryptomonas sp. Relationships between the N/C ratio and (a) chl a quota $q_{\text {chl ar }}$ (b) PE quota $q_{\mathrm{PE}}$ and (c) PE/chl a ratio in LN-HN and HN-LN cultures. For clarity, only measurements obtained just before, during, and just after transient phases are plotted. Larger symbols indicate initial conditions

Proteins associated with both the light (pigments) and dark (carboxylase) reactions of photosynthesis are known to be degraded under N-limiting conditions. The strong correlations between the N/C ratio and the quotas of $\mathrm{N}$-rich pigment complexes chl a and $\mathrm{PE}$ under N-limited conditions are thus not surprising (Fig. 8). The variations in these pigment contents were
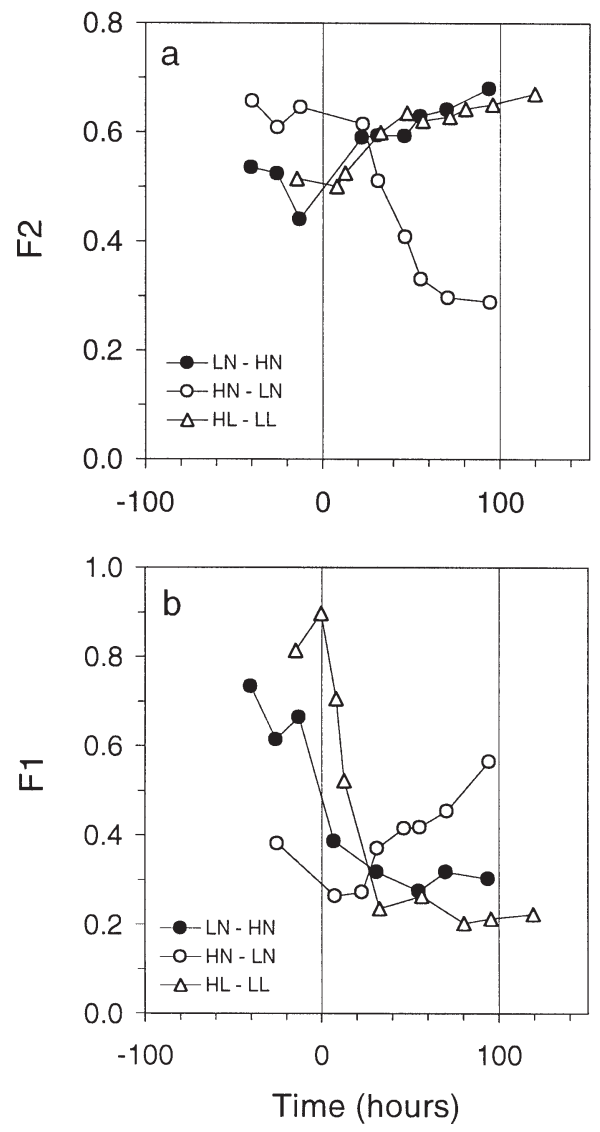

Fig. 9. Cryptomonas sp. Changes in (a) F1 and (b) F2 in $\mathrm{LN}-\mathrm{HN}, \mathrm{HN}-\mathrm{LN}$, and HL-LL cultures over time (see 'Results')

similar in $\mathrm{N}$ and light stresses in the growth conditions imposed of this experiment. In the case of $\mathrm{N}$ enrichment, a significant increase in $q_{\mathrm{chl}}$ and $q_{\mathrm{PE}}$ was observed within the first $10 \mathrm{~h}$. As this period was less than the division time, the changes in pigment contents clearly arose from actual synthesis. The reverse was true in the case of $\mathrm{N}$ deprivation, during which there was an active degradation of the light-harvesting complexes. In N-rich cells $q_{\text {PE }}$ was 4 -fold greater than $q_{\text {chl a }}$. It remained 1.5-fold higher when cells were Ndeprived. Our data also show that the PE relative variations were greater than those of chl $a$, both during pigment synthesis and degradation, since the PE/chl $a$ ratio did not remain constant with time.

\section{Relationship between $q_{\mathrm{N}}, q_{\mathrm{PE},}$ and $q_{\mathrm{chl} \text { a }}$ and $\mu_{V}$}

In the context of this study, it was necessary to verify to what extent growth was strictly limited by nitrogen in HN-LN and LN-HN. The concept of single nutrient 
limitation has been successfully formalized by the internal quota model, which hypothesizes that growth depends only on the amount of the internal limiting nutrient. Droop's (1968) model applies correctly to growth in the steady state and when the algal population is defined as a biomass (rather than as a cell density) and the internal quota as a mass per unit biomass (rather than as mass per cell) (see Droop 1979). It can be seen that during the transient phase following the $\mathrm{N}$ $(30 \mathrm{~h})$ and light $(10 \mathrm{~h})$ perturbations, growth rate estimated from cell density differed markedly from that estimated from biovolume (Fig. 4). The difference between $\mu_{v}$ and $\mu_{n}$ arises essentially from the transient variation of the cell volume just after perturbation, and from the opposite effects of $\mathrm{N}$ stress on cell division and cell size. Given the nearly invariant ratio between cell carbon and cell volume (Fig. 6c), the somatic growth rate can reasonably be represented by the variation in time of biovolume, $\mu_{V}$.

In the $\mathrm{N}$-limited cultures, $\mu_{V}$ was measured before and during the $\mathrm{N}$ perturbations, i.e. in non-steady conditions. Despite this, we have fitted Droop's model to the data in Fig. 10a, from which 2 relationships emerge, one for $\mathrm{N}$ enrichment and one for $\mathrm{N}$ deprivation. The small but significant discrepancy between these 2 relationships shows that during the transient phase following perturbation the relationships between the nitrogen quota and $\mu_{v}$ are not the same under $\mathrm{N}$ enrichment and $\mathrm{N}$ impoverishment. This results from the delay between the external nitrogen variation and the subsequent changes in internal quota and growth rate. In the case of $\mathrm{N}$ supply, this delay most probably corresponds to the time necessary for assimilation processes $\left(\mathrm{NO}_{3}\right.$ and $\mathrm{NO}_{2}$ reduction, amination, protein synthesis). The steady-state relationship between $\mu_{v}$ and $q_{\mathrm{N}}$ should thus lie between the 2 curves in Fig. 10a. It can be seen that for a given $\mathrm{N}$ quota, the predicted growth rate is under estimated in the case of $\mathrm{N}$ enrichment and over estimated in the case of $\mathrm{N}$ deprivation. Despite the discrepancy observed in the Droop relationships between LN-HN and HN-LN, growth was strictly N-limited in both cultures.

A significant relationship exists between growth rate and the $\mathrm{PE} / \mathrm{chl}$ a ratio under $\mathrm{N}$-limited conditions (Fig. 10b). This is in accordance with the previously described correlation between the $\mathrm{PE} / \mathrm{chl}$ a ratio and $q_{\mathrm{N}}$, and between $q_{\mathrm{N}}$ and growth rate. Two distinct relationships correspond to $\mathrm{N}$ enrichment and deprivation conditions, reflecting the facts firstly that $q_{\mathrm{PE}}$ and $q_{\mathrm{chl}}$ a were not in equilibrium with growth rate, as was the case for $q_{\mathrm{N}}$ (see Fig. 10a), and secondly that the priority given to the degradation and synthesis of chl $a$ and $\mathrm{PE}$ was not the same under $\mathrm{N}$ deprivation and enrichment. This can also be seen from the opposing curves in Fig. 8c. In the case of $\mathrm{N}$ supply, chl $a$ and PE were immediately synthesized at the same rate, while later $\mathrm{PE}$ was preferentially synthesized to increase the nitrogen reserve. In the case of $\mathrm{N}$ limitation, chl a and $\mathrm{PE}$ were initially degraded at the same rate, while later PE was preferentially degraded to support the N demand. The relationships in Fig. 10b are linear instead of curvilinear, due to the fact that both chl $a$ and PE cell contents display curvilinear relationships with growth rate (data not shown).

\section{Relationships between optical properties of Cryptomonas sp. and $\mu_{v}$}

Under $\mathrm{N}$ limitation, F1 (the presumed extent of PE-chl a coupling, Fig. 11a) was poorly correlated with the growth rate of Cryptomonas sp., in contrast to F2 (relative PE-chl a quota and presumable intensity of PE-chl a coupling, Fig. 11b). The weak correlation in Fig. 11a can be interpreted by examining F1 (Eq. 7). The $\mathrm{F} 1$ ratio is composed of 3 terms which, under $\mathrm{N}$
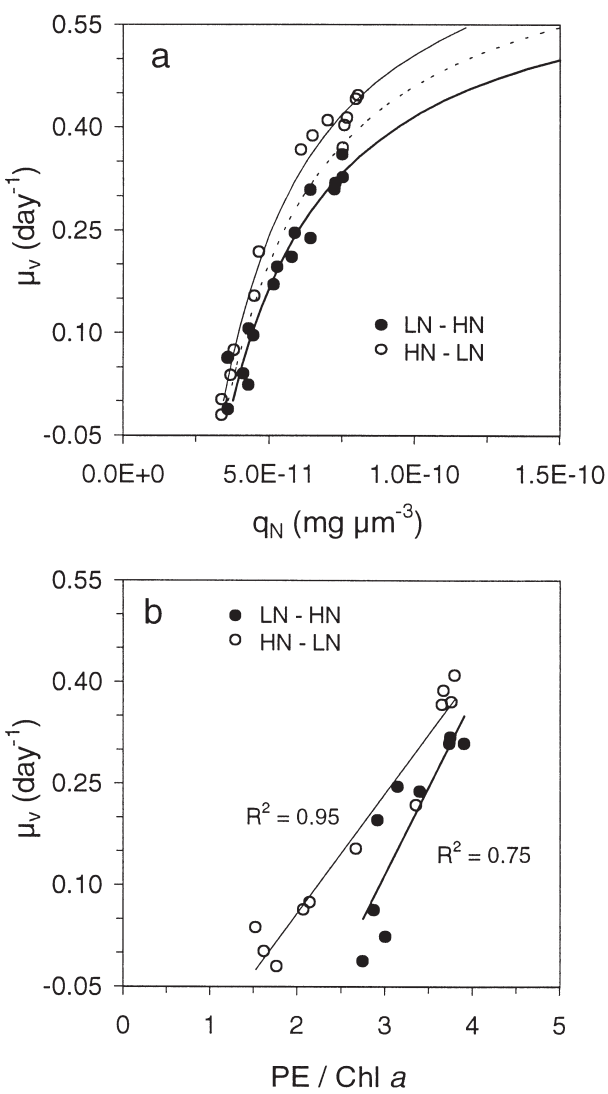

Fig. 10. Cryptomonas sp. Relationships between growth rate $\mu_{V}$ and (a) nitrogen quota and (b) PE/chl a ratio in LN-HN and HN-LN cultures. Curves in (a) represent fit of Droop's model (1968) to data 

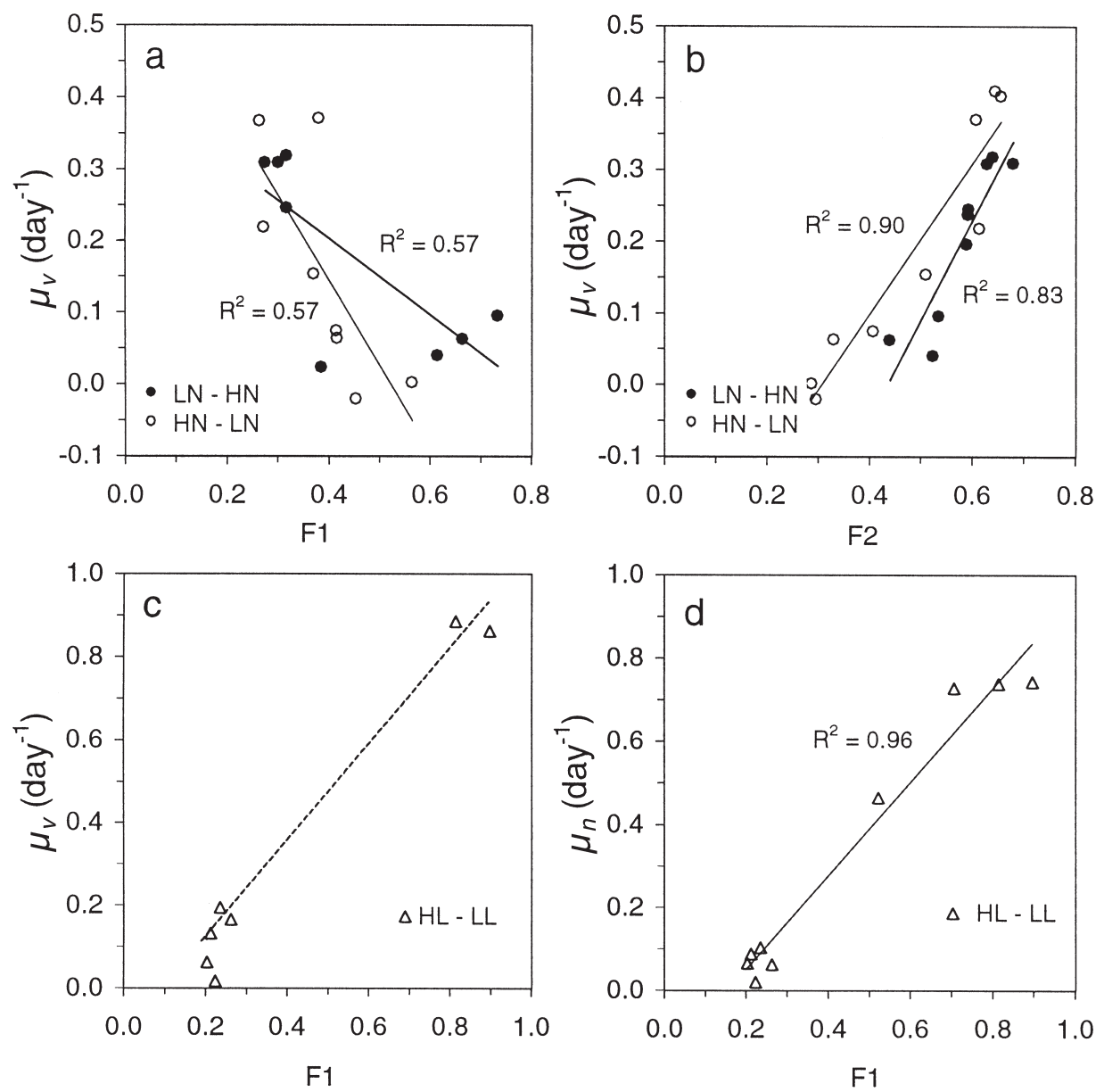

Fig. 11. Cryptomonas sp. Relationships between growth rate, $\mu_{V}$ and (a) F1 and (b) F2 in N-limited cultures and between F1 and (c) $\mu_{v}$ and (d) $\mu_{n}$ under light-limiting conditions

stress, may vary. The most simple and immediate pattern would be where only $K_{\mathrm{TE}-\mathrm{chl} a^{\prime}}$ the rate of energy transfer from PE to chl $a$, is influenced by $\mathrm{N}$ status. Studies have nevertheless showed that PSII activity, and thus $\phi_{\mathrm{F}_{\mathrm{chl}} \mathrm{a}^{\prime}}$ is affected by $\mathrm{N}$ deprivation (Kolber et al. 1988). Effects of $K_{\mathrm{T}_{\mathrm{PE}-\mathrm{chl} \text { a }}}$ and $\phi_{\mathrm{F}_{\mathrm{chl}} \text { a }}$ variations are synergetic, because they are both placed as the denominator of the $\mathrm{F} 1$ ratio. The fluorescence rate of $\mathrm{PE}, K_{\mathrm{F}_{\mathrm{PE}}}$ may also be subject to variations if free phycoerythrin molecules appear within the chloroplast as a consequence of LHC protein degradation. In this case, a relaxation in the so-called 'concentration quenching' may lead to a significant increase in $K_{\mathrm{F}}$ (enhanced fluorescence) and, therefore, a disproportionate increase in $\mathrm{F} 1$ relatively to the decrease in $K_{\mathrm{TE}-\mathrm{chl}}$. These combined effects, and the fact that

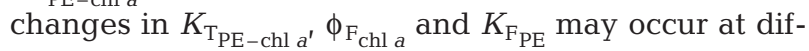
ferent times as the intensity of $\mathrm{N}$ limitation increases can explain why the relationship between $\mu_{V}$ and F1 is scattered.
Conversely, the strong correlation between $\mu_{V}$ and F2 (Eq. 8 and Fig. 11b) arises from: (1) the wide range in variation of the absorption ratio a(547)/a(438) under $\mathrm{N}$-limitation, and (2) the fact that this ratio is expected to vary with energy-transfer efficiency, $\phi_{\mathrm{T}_{\mathrm{PE}-\mathrm{chl}} \text {. }}$ As for $q_{\mathrm{N}}$ and the PE/chl a ratio, 2 relationships between $\mu_{V}$ and F2 can be distinguished, reflecting different dynamics of $\mathrm{N}$ mobilization in LN-HN and HN-LN. In the case of $\mathrm{N}$ addition, the growth enhancement is triggered by a preferential synthesis of $\mathrm{PE}$, whereas under $\mathrm{N}$ restriction, the PE pool is preferentially degraded to allow the cell to maintain an optimal growth rate.

Given the small impact of the light shift-down on the N/C ratio (Fig. 6a), light limitation on growth was not reflected by significant relationships between this ratio and F1 or F2 (data not shown). This indicates that when photoacclimation takes place, the syntheses of PE and chl $a$ are enhanced at rates that do not greatly modify their initial proportions. This confirms the observation that the PE/chl a ratio was not greatly affected by the 
light change (Fig. 7c). In contrast, the energy transfer between PE and chl a seemed to be greatly increased under a low-light regime, so that the relations between F1 and the growth and division rates are positive (Fig. 11c,d). During light variations, energy transfer may be controlled by state transition, i.e. dissociation/association of parts of PS II antenna. In this case, the $\mathrm{F} 1$ ratio is certainly a good indicator of energy transfer $\left(K_{\mathrm{T}_{\mathrm{PE}-\mathrm{chl} a}}\right)$, because (1) $\phi_{\mathrm{F}_{\mathrm{chl} \text { a }}}$ does not vary as a consequence of photoacclimation (see e.g. Falkowski et al. 1994), and (2) $K_{\mathrm{FPE}}$ is not expected to vary as a function of transition state, given that, in this case, phycoerythrin is likely to remain bounded to antenna proteins whether the latter are attached to the antenna or not.

The light shift-down had a drastic and transient effect on cell size (Fig. 5). During the $24 \mathrm{~h}$ following light stress, $q_{\mathrm{C}}$ was not stable (Fig. 6c) and $\mu_{V}$ was not a good estimator of somatic growth rate (Fig. 4). In Fig. $11 \mathrm{c}$, the relationship between $\mu_{V}$ and F1 applies only to the data acquired before light reduction and 24 h later.

The relationships shown in Fig. 11 were acquired in unsteady perturbed cultures and are rather noisy. They nevertheless show that $\mathrm{N}$ and light stresses have different effects on the coupling between PE and chl a. When growth is N-limited, a reduction in the amount of energy transferred from PE to chl $a$ is achieved by reducing the proportion of $\mathrm{PE}$ to chl $\mathrm{a}$ and, to a lesser extent, by decreasing the PE-chl a coupling efficiency. Under light limitation, the total amounts of chl $a$ and $\mathrm{PE}$ are markedly increased, but their relative proportion is less affected, so that the energy transfer between them is essentially regulated through coupling efficiency. These different kinds of regulations are in agreement with the hypothesis that PE, like other accessory pigments, plays a role in $\mathrm{N}$ sequestration. Under $\mathrm{N}$ limitation, $\mathrm{C}$ fixation is reduced to balance the internal demand, which is subject to the $\mathrm{N}$ assimilation rate. Preferential degradation of $\mathrm{PE}$ allows the cell to reduce its photosynthetic capacity and to sustain the $\mathrm{N}$ demand with the catabolites arising from such degradation. Under non-limiting nutrient conditions, the proportion of $\mathrm{PE}$ to $\mathrm{chl} \mathrm{a}$ is less affected by the light regime, because there is no need for extra nitrogen to sustain optimal growth, and the energy transfer from the former to the latter is regulated through their coupling efficiency. Because of the cell's adaptation to $\mathrm{N}$ or light limitation, light-dependent growth is best correlated with F1, whereas N-limited growth is best correlated with F2.

Acknowledgements. We thank Gilbert Malara for technical help, Kadija Oubelkheir for pigment analysis, Flavienne Bruyant for fluorescence spectra acquisition, and Patrick
Chang for improving the English. We also thank the anonymous reviewers for their comments. This research was supported by funds from the PROSOPE group project (PROOF French Program), by the CNRS, and by the University of Florence (Fondi di Ateneo, ex-MURST $60 \%$ ).

\section{LITERATURE CITED}

Allen MM, Hutchison F (1980) Nitrogen limitation and recovery in the cyanobacterium Aphanacapsa 6308. Arch Microbiol 128:1-7

Allen MM, Law A, Evans H (1990) Control of photosynthesis during nitrogen depletion and recovery in a non-nitrogenfixing cyanobacterium. Arch Microbiol 153:428-431

Bernard O, Malara G, Sciandra A (1996) The effects of a controlled fluctuating nutrient environment on continuous cultures of phytoplankton monitored by a computer. J Exp Mar Biol Ecol 197:263-278

Boussiba S, Richmond AE (1980) C-phycocyanin as a storage protein in the blue-green algae Spirulina platensis. Arch Microbiol 125:143-147

Campbell D (1996) Complementary chromatic adaptation alters photosynthetic strategies in the cyanobacterium Calothrix. Microbiology 142:1255-1263

Carr NG (1988) Nitrogen reserves and dynamic reservoirs in cyanobacteria. In: Rogers LJ, Gallon JR (eds) Biochemistry of the algae and cyanobacteria. Clarendon Press, Oxford, p 13-21

Collier JL, Grossman AR (1992) Chlorosis induced by nutrient deprivation in Synechococcus sp. strain PCC 7942: not all bleaching is the same. J Bacteriol 174:4718-4726

Collier JL, Grossman AR (1994) A small polypeptide triggers complete degradation of light-harvesting phycobiliproteins in nutrient-deprived cyanobacteria. EMBO J 13: 1039-1047

Droop MR (1968) Vitamin $B_{12}$ and marine ecology. IV. The kinetics of uptake growth and inhibition in Monochrysis lutheri. J Mar Biol Assoc UK 48:689-733

Droop MR (1979) On the definition of X and Q in the cell quota model. J Exp Mar Biol Ecol 39:203

Duke CS, Allen MM (1990) Effect of nitrogen starvation on polypeptide composition, ribulose-1,5-bisphosphate carboxylase/oxygenase, and thylakoid carotenoprotein content of Synechocystis sp. strain PCC6308. Plant Physiol 94: $752-759$

Falkowski PG, Greene R, Kolber Z (1994) Light utilization and photoinhibition of photosynthesis in marine phytoplankton. In: Baker NR, Bowyer JR (eds) Photoinhibition of photosynthesis: from molecular mechanisms to the field. Bios Scientific, Cambridge, p 407-432

Foulds IJ, Carr NG (1977) A proteolitic enzyme degrading phycocyanin in the cyanobacterium Anabaena cylindrica. FEMS Lett 2:117-119

Gantt E, Edwards MR, Provasoli L (1971) chloroplast structures of the Cryptophyceae. J Cell Biol 48:280-290

Glazer AN (1981) Photosynthetic accessory proteins pigment with bilin prosthetic groups. In: Conn EE, Stumpf PK (eds) The biochemistry of plants. Academic Press, New York, p 51-96

Glibert PM, Kana TM, Olson RJ, Kirchman DL, Alberte RS (1986) Clonal comparisons of growth and photosynthetic responses to nitrogen availability in marine Synechococcus sp. J Exp Mar Biol Ecol 101:199-208

Grossman AR (1990) Chromatic adaptation and the events involved in phycobilisome biosynthesis. Plant Cell Environ 13:651-666 
Grossman AR, Schaefer MR, Chiang GG, Collier JL (1994) The responses of cyanobacteria to environmental conditions: light and nutrients. In: Bryant DA (ed) The molecular biology of cyanobacteria. Kluwer, Dordrecht, p 641-675

Kana TM, Glibert PM (1987a) Effect of irradiances up to $2000 \mu \mathrm{E} \mathrm{m}^{-2} \mathrm{~s}^{-1}$ on marine Synechococcus WH7803-I. Growth, pigmentation and cell composition. Deep-Sea Res 34:479-495

Kana TM, Glibert PM (1987b) Effect of irradiances up to $2000 \mu \mathrm{E} \mathrm{m}^{-2} \mathrm{~s}^{-1}$ on marine Synechococcus WH7803-II. Photosynthetic responses and mechanisms. Deep-Sea Res 34:497-516

Kana TM, Feiwel NL, Flynn LC (1992) Nitrogen starvation in marine Synechococcus strains: clonal differences in phycobiliprotein breakdown and energy coupling. Mar Ecol Prog Ser 88:75-82

Kolber ZJ, Zehr JP, Falkowski PG (1988) Effect of growth irradiance and nitrogen limitation on photosynthetic energy conversion in photosystem II. Plant Physiol 88:923-929

Lazzara L, Bricaud A, Claustre H (1996) Spectral absorption and fluorescence excitation properties of phytoplanktonic populations at a mesotrophic and an oligotrophic site in the tropical North Atlantic (EUMELI program). Deep-Sea Res (I) 43:1215-1240

Liebig J (1840) Chemistry in its application to agriculture and physiology, 4th edn. Taylor and Walton, London

MacColl R, Berns DS, Gibbons O (1976) Characterization of cryptomonad phycoerythrin and phycocyanin. Arch Biochem Biophys 177:265-275

Mantoura RFC, Repeta DJ (1997) Calibration methods for HPLC. In: Mantoura RFC, Jeffrey SW, Wright SW (eds) Phytoplankton pigments in oceanography: guidelines to modern methods. UNESCO, Rome, p 407-428

Editorial responsibility: Otto Kinne (Editor), Oldendorf/Luhe, Germany
Morel A, Bricaud A (1981) Theoretical results concerning light absorption in a discrete medium, and application to specific absorption of phytoplankton. Deep-Sea Res 28A: 1375-1393

Rowan KS (1989) Photosynthetic pigments of algae. Cambridge University Press, Cambridge

Sciandra A, Gostan J, Collos Y, Descolas-Gros C, Leboulanger C, Martin-Jézéquel V, Denis M, Lefèvre D, CopinMontégut C, Avril B (1997) Growth compensating phenomena in continuous cultures of Dunaliella tertiolecta limited simultaneously by light and nitrate. Limnol Oceanogr 42:1325-1339

Tandeau de Marsac N, Houmard J (1988) Complementary chromatic adaptation; physiological conditions and action spectra. Methods Enzymol 167:318-328

Tandeau de Marsac N, Houmard J (1993) Adaptation of cyanobacteria to environmental stimuli: new steps towards molecular mechanisms. FEMS Microbiol Rev 104:119-190

Turpin DH (1991) Effects of inorganic $N$ availability on algal photosynthesis and carbon metabolism. J Phycol 27:14-20

Van de Hulst HC (1957) Light scattering by small particles. Wiley, New York

Vidussi F, Claustre H, Bustillos-Guzmàn J, Cailliau C, Marty JC (1996) Rapid HPLC method for determination of phytoplankton chemotaxinomic pigments: separation of chlorophyll $a$ from divinyl-chlorophyll $a$ and zeaxanthin from lutein. J Plankton Res 18:2377-2382

Woods NB, Haselkorn R (1980) Control of phycobiliprotein proteolysis and heterocyst differentiation in Anabaena. J Bacteriol 141:1375-1385

Wyman M, Gregory RPF, Carr NG (1985) Novel role for phycoerythrin in a marine cyanobacterium, Synechococcus strain DC2. Science 230:818-820

Submitted: August 26, 1999; Accepted: February 15, 2000 Proofs received from author(s): June 26, 2000 